\title{
The masked onset priming effect in naming: Computation of phonology or speech planning?
}

\author{
SACHIKO KINOSHITA and ANNA WOOLLAMS \\ Macquarie University, Sydney, New South Wales, Australia
}

\begin{abstract}
We investigated factors that modulate the presence of the masked onset priming effect in three naming experiments. In Experiment 1, we showed that the masked onset priming effect is found with regular words, but not with exception words, replicating the finding reported by Forster and Davis (1991). In Experiment 2, we used the conditional naming task in which words are mixed with nonwords and participants are instructed to name the item only if it is a word. The masked onset priming effect was eliminated in this experiment, but the regularity effect remained. In Experiment 3, regular and irregular words were mixed randomly, rather than in separate blocks as in Experiment 1. This reduced the size of the regularity effect, and the masked onset priming effect was again absent. We argue that these results, taken as a whole, are better interpreted within the view that the masked onset priming effect has its origin in the preparation of a speech response, rather than within the original dual-route interpretation proposed by Forster and Davis.
\end{abstract}

Recent research on visual word recognition has highlighted the issue of whether phonology is computed from orthography in parallel or sequentially. Many current computationally implemented models of reading aloud, such as Plaut and colleagues' (Plaut, McClelland, Seidenberg, \& Patterson, 1996) parallel distributed processing (PDP) model or Zorzi and colleagues' (Zorzi, Houghton, \& Butterworth, 1998) connectionist dual-route model, assume that phonology is derived from orthography in parallel across the letter string. In contrast, Coltheart and colleagues (M. Coltheart, Rastle, Perry, Langdon, \& Ziegler, 2001; M. Coltheart, Woollams, Kinoshita, \& Perry, 1999) have pointed out that their dual-route cascaded (DRC) model is the only model that incorporates a serial assumption. Because this is one of the major features that distinguishesthe DRC model from other computational models of reading aloud, it is important to establish the empirical basis of this claim.

To date, two sequential effects have been simulated successfully by the DRC model. The left-to-right regularity effect refers to the finding that in naming, the cost (in latency or errors) of the exceptional spelling-to-sound correspondence is greater for irregularities that occur early in a word (e.g., heir) than late in a word (e.g., debris) (M. Coltheart \& Rastle, 1994; Cortese, 1998; Rastle \& Coltheart, 1999). The masked onset priming effect refers to the benefit in naming latency due to a match of the onset

This research was funded by an Australian Research Council grant (small ARC 1999). We are grateful to Ken Forster, Mike Cortese, Bob Lorch, and Colin MacLeod for helpful comments on the earlier version of the paper. Correspondence concerning this article should be addressed to S. Kinoshita, Macquarie Centre for Cognitive Science and the Department of Psychology, Macquarie University, Sydney, NSW 2109, Australia (email: sachiko@maccs.mq.edu.au). phonemes between the prime and target: For example, the target word SAVE is named faster when preceded by the prime sink, which shares just the onset with the target, than by the prime farm, which shares no letters with the target (Forster \& Davis, 1991). ${ }^{1}$ Like the regularity effect, this effect too is position dependent in that the benefit of a match is observed only in the initial phoneme, not in the later phonemes (Forster \& Davis, 1991; Kinoshita, 2000).

Both the left-to-right regularity effect and the masked onset priming effect have been interpreted within the dualroute framework as reflecting the operation of the nonlexical route in naming (Coltheart et al., 1999; Forster \& Davis, 1991). The basic premise of this framework is that there are two ways of computing phonology: the lexical route, which involves the retrieval of whole-word phonology stored in the phonologicaloutput lexicon (which is accessed via a connection from the orthographic input lexicon), and the nonlexical route, which computes phonology by means of application of spelling-to-sound correspondence rules. It is assumed that whereas the lexical route retrieves phonology for the whole word in parallel, the nonlexical route translates graphemes into phonemes serially, from left to right, across the letter string. These two asynchronous sources of input are integrated into a single common set of phoneme units.

The sequential nature of the regularity effect and the masked onset effect fall out quite naturally from this assumption. Specifically, for low-frequency words with irregularities in the early position (e.g., heir), the conflicting nonlexicalinformation $(/ \mathrm{h} /)$ may arrive at the phoneme system before lexical processing is completed, causing a cost to the reader. When the irregularity occurs in a later position (e.g., debris), the lexical route will likely finish retrieving the phonology before conflicting nonlexical information (/s/) arrives at the phoneme system. Similarly, the masked 
onset priming effect is explained in terms of the nonlexical route, delivering conflicting phonology to the phoneme system for early, but not for later, mismatching letters. The DRC model has successfully simulated both the leftto-right regularity effect (M. Coltheart \& Rastle, 1994; Rastle \& M. Coltheart, 1999; but see Zorzi, 2000, for a simulation of this effect within a parallel model) and the masked onset priming effect (M. Coltheart et al., 1999) using this assumption.

An alternative account of the sequential nature of masked onset priming has been proposed by Kinoshita (2000), who has suggested that the effect has a locus farther downstream than the orthography-phonology computation process - namely, in the process of planning a speech response. This argument is based on the evidence from the speech production literature. It is recognized that in producing natural speech, the phonology retrieved from the lexicon is decomposed and then inserted into metrical frames that may not respect word boundaries (e.g., in the phrase Police demand it, demand it would be grouped into demandit). This process is called the segment-to-frame association process, and it is widely accepted that this process occurs left-to-right (cf. Levelt, Roelofs, \& Meyer, 1999). Experimental support for this claim can be found in a study (conducted using Dutch stimuli) by Meyer (1991). Subjects in this study were required to utter just one of the words from either a homogeneous list, in which the items shared segments (e.g., hut, heel, hop), or a heterogeneous list (e.g., hut, dance, pole). The shared segment was either the onset or the rime, and the critical finding was that a facilitation in production latency occurred only when the words shared the initial segments; sharing the rime did not result in any facilitation. Meyer interpreted the result to suggest that the segment-to-frame association process proceeds from left to right and that later segments cannot be prepared until the initial segments are selected. Kinoshita (2000) suggested that the sequential nature of the masked onset priming effect may have its origin in this speech planning process: That is, a mismatch in phonemes between the prime and target holds up the segment-to-frame association process when that mismatch is in the initial position, but not when it is in later positions. It should be noted that if the sequential nature of the masked onset priming is farther downstream than the orthography-to-phonology computation process, the existence of the effect does not constitute evidence against models that assume parallel computation of phonology.

Although the speech-planning account is consistent with the sequential nature of the masked onset priming effect, two findings are not easily handled by this account and are more easily interpretable with the dual-route account proposed by Forster and Davis (1991). One is the absence of the masked onset priming effect for exception words - that is, words that contain exceptional spellingto-sound correspondences such as PINT (Forster \& Davis, 1991, Experiment 4). The second is that the masked onset priming effect for regular words is eliminated in a conditional naming task (Forster \& Davis, 1991, Experiment 6).
Within the dual-route framework, the regularity effect is assumed to reflect the fact that, for exception words, the phonology computed from orthography based on spellingto-sound correspondence rules and that retrieved from the phonological output lexicon conflict, and that resolving this conflict takes time. If the locus of the masked onset priming effect is found solely in the process of generating a speech output from a phonologicalcode, it is unclear why the effect is not observed for exception words. That is, if the segment-to-frame association process starts after the conflict in phonology generated for irregularly spelled words is resolved, then within the view that the masked onset priming effect has its origin in the speech planning process, there is no reason why the masked onset priming effect would be absent for exception words. In contrast, this finding is easily explained within the dual-route framework by the assumption that masked onset priming effects are observed only for those items that are named via the sequential nonlexical route and that to pronounce an exception word correctly, the output from the nonlexical route must be ignored or actively inhibited, as suggested by Forster and Davis (1991).

Before this finding is accepted as evidence for the dualroute interpretation, however, it should be pointed out that the masked onset priming effect is sensitive to a number of other factors. For example, Forster and Davis (1991) reported that word frequency and number of orthographic neighbors (Coltheart's $N$ ) modulate the presence of the masked onset priming effect. In Forster and Davis's Experiment 4, half of their exception words were described as "orthographically strange" words - that is, words with unusual orthographic structure as well as exceptional spelling-to-sound correspondence (Seidenberg, Waters, Barnes, \& Tanenhaus, 1984), such as fete, aisle. These orthographically strange words typically contain less common letter combinations and have few orthographic neighbors (i.e., they are low $N$ ). It is possible therefore that the absence of the masked onset priming effect was due to their low $N$, rather than to the exceptional spelling-to-sound correspondence per se. Thus, one aim in the present study was to ascertain whether masked onset priming effects are indeed absent for exception words when regular and exception words are matched on word frequency and $N$. This was tested in Experiment 1.2

The second finding that causes problems for the speechplanning account is that the masked onset priming effect for regular words is eliminated in a conditionalnaming task (Forster \& Davis, 1991, Experiment 6). In this task (also referred to as the go/no-go naming task), subjects are presented with a random mix of words and nonwords and are instructed to name the item only when it is a word. Forster and Davis's interpretation of this finding was that in this task, the nonlexical route is prevented from exercising its influence on the pronunciation of the letter string, either because the nonlexical route is "turned off," or because the output of this route is ignored. We suspected, however, that this interpretation was probably incorrect. This is because it predicted that the regularity effect would also be eliminated in this task. That is, because the regularity effect was 
assumed to reflect a cost involved in resolving the conflict in the pronunciations generated by the lexical and nonlexical routes, if the nonlexical route was turned off (or its output is inhibited) in the conditional naming task, there should be no regularity effect in this task. Contrary to this prediction, however, we have unpublished evidence that the size of the regularity effect is not reduced in the conditional naming task; we note also that Hino and Lupker (2000) recently reported such a finding. These failures of the regularity effect to be eliminated in the conditional naming task clearly raise problems for the interpretation that the nonlexical route is turned off (or that the output of the nonlexical route is ignored) in this task. Before discussing this issue, however, we note that these two results (the absence of the masked onset priming effect for regular words and the finding of the regularity effect in the conditional naming task) were obtained in separate experiments. It was therefore considered important to establish the empirical basis of these two findings in the same experiment. This was the aim of Experiment 2.

To summarize, there are two findings that suggest problems for the speech-planning account of the masked onset priming effect-namely, the absence of the effect for exception words and the fact that the effect for regular words is eliminated in the conditional naming task. The aim of the present study was to empirically establish these two findings with better controls than in previous studies, with a view to evaluating the dual-route versus speechplanning interpretation of the masked onset priming effect.

\section{EXPERIMENT 1}

Our aim in Experiment 1 was to test whether the masked onset priming effect could be found for regular words but not for exception words, matched on all factors considered to be relevant for obtaining the effect-namely, frequency, $N$, and the initial phoneme.

\section{Method}

Subjects. Twenty-four 3rd-year Macquarie University students participated in this experiment as part of a course requirement. All subjects were native Australian English speakers.

Design. The experiment constituted a 2 (target type: regular vs. exception) $\times 2$ (prime type: onset matched vs. control) design, with both factors manipulated within subjects. The dependent variables were naming latency and error rate.

Materials. The critical stimulus materials were 28 low-frequency regular and 28 low-frequency exception words. They were all monosyllabic, 4 or 5 letters long, had a written frequency of 13 per million or less (Kučera \& Francis, 1967), and had a single-letter consonant onset (e.g., vINE). This last selection criterion was included because in an earlier study (Kinoshita, 2000) the masked onset priming effect was found to be absent for words with complex onsets (e.g., BLISS). The regular words followed the regular grapheme-phoneme mapping rules as defined by M. Coltheart, Curtis, Atkins, and Haller (1993) and were pronounced correctly by the DRC model's nonlexical route. The exception words did not follow these rules and were pronounced incorrectly by the DRC model's nonlexical route. Also, the regular words were chosen so that they had at least three friends, because in an earlier unpublished study, Kinoshita (2001) had found that the masked onset priming effect was reliable only for such words (see also the Discussion section of Experiment 3). This requirement was not met by the exception words because they typically have few friends (see also note 2). The regular and exception words were matched pairwise on initial phoneme and length and on mean frequency and Coltheart's $N$ for the whole set. The characteristics of the critical targets are shown in Table 1, and the actual items are listed in the Appendix.

Each target word set was divided into two matched sets (A and B) of 14 items. The assignment of the sets to the two prime type conditions (onset matched vs. control) was fully counterbalance d across subjects, so that each subject saw a target word once, and each word occurred in each prime type condition once between every pair of subjects.

There were also 28 words used as primes. They were 4- and 5-letter words of low-to-medium frequency, selected to have the same onsets as the targets. In the onset-matched condition, the primes were paired with the targets with the same onset; in the control condition, they were re-paired so that the onsets of the primes and targets were different.

Apparatus and Procedure. The subjects were tested individually, seated approximately $40 \mathrm{~cm}$ in front of an NEC Multisync 4FG monitor, on which the stimuli were presented.

At the outset of the experiment, the subjects were told that a list of words would be shown on the computer screen, one at a time, preceded by a series of hash signs (\#\#\#\#\#\#) as a warning signal. No mention was made of the prime word presented between the hash signs and the target. The subjects were instructed to read aloud each target word, presented in uppercase letters, as soon as it appeared on the screen. Stimuli were presented in a different random order for each subject, following the six practice and two buffer stimuli selected according to the same criteria as the critical stimuli.

Instructions and stimuli were presented and reaction time (RT) data were recorded to the nearest millisecond using the DMASTR display system developed by K. I. Forster and J. C. Forster (1990) at Monash University and the University of Arizona, running on a Deltacom 486 IBM-compatible computer. RTs were recorded with an amplitude voice key fitted to each subject and held at a constant distance from the mouth throughout the experiment by means of a headset. Naming errors and possible measurement errors due to inappropriate voice key activation (e.g., coughing) were recorded manually by the experimenter.

Each trial started with the presentation of a forward mask (\#\#\#\#\#\#) for $500 \mathrm{msec}$, followed by a prime presented in lowercase letters for four cycles of the screen refresh rate $(56 \mathrm{msec})$; then a target was presented in uppercase letters. The target remained on the screen for a maximum of 2,000 msec, or until the voice key was triggered by the subject's response. Following a $300-\mathrm{msec}$ blank screen, the next trial started. The subjects were given no feedback on either naming latencies or error rates during the experiment.

The regular words and the exception words were presented in two separate blocks. Half of the subjects did the regular word block first; the other half did the exception word block first.

\section{Results and Discussion}

For this and subsequent analyses, the preliminary treatment of trials was as follows. Any trial on which a subject

Table 1

Statistical Properties of Target Words

\begin{tabular}{lcrccc}
\hline Target Type & kffreq & \multicolumn{1}{c}{$N$} & Friend $N$ & Enemy $N$ & Length \\
\hline Regular & 5.28 & 10.00 & 10.07 & .25 & 4.11 \\
Exception & 7.46 & 8.57 & 1.21 & 5.00 & 4.04 \\
\hline
\end{tabular}

Note-kffreq, number of occurrences per million based on Kučera \& Francis (1967); $N$, number of orthographic neighbors; Friend $N$, number of words sharing the body that is pronounced the same way; Enemy $N$, number of words sharing the body which has a different pronunciation; Length, number of letters. 
or voice key error occurred was excluded from the latency analysis. To reduce the effects of outliers, spuriously long or short RTs were trimmed to the cutoff value of two standard deviations above or below the mean for each subject. Analyses treating subjects as the random variable $\left(F_{\mathrm{s}}\right)$ and treating items as a random variable $\left(F_{\mathrm{i}}\right)$ are reported, and an effect was considered to be significant when both analyses were significant at the .05 level.

The mean naming latencies and percent error rates are presented in Table 2 .

Naming latency. We performed planned contrasts testing (1) the regularity effect, (2) the masked onset priming effect for regular words, and (3) the masked onset priming effect for exception words. Averaged across prime type, the regularity effect was $70 \mathrm{msec}$ and was highly significant $\left[F_{\mathrm{s}}(1,23)=64.83, M S_{\mathrm{e}}=1,807.53 ; F_{\mathrm{i}}(1,54)=\right.$ $\left.62.18, M S_{\mathrm{e}}=2,234.87\right]$. The 14-msec masked onset priming effect for regular words was significant $\left[F_{\mathrm{s}}(1,23)=\right.$ $\left.7.32, M S_{\mathrm{e}}=311.83 ; F_{\mathrm{i}}(1,27)=4.13, M S_{\mathrm{e}}=706.35\right]$. The 4-msec masked onset priming effect for exception words was nonsignificant $\left[F_{\mathrm{s}}(1,23)<1.0, M S_{\mathrm{e}}=417.13\right.$; $\left.F_{\mathrm{i}}(1,27)<1.0, M S_{\mathrm{e}}=2,055.17\right]$.

Error rate. The same planned contrasts as for the naming latency data showed that, averaged across the prime type, the regularity effect was significant $\left[F_{\mathrm{s}}(1,23)=\right.$ $\left.11.52, M S_{\mathrm{e}}=20.27 ; F_{\mathrm{i}}(1,54)=8.28, M S_{\mathrm{e}}=32.95\right]$. The masked onset priming effect for regular words was nonsignificant $\left[F_{\mathrm{s}}(1,23)=1.87, M S_{\mathrm{e}}=5.10 ; F_{\mathrm{i}}(1,27)=1.00\right.$, $\left.M S_{\mathrm{e}}=11.13\right]$. The masked onset priming effect for exception words was also nonsignificant $\left[F_{\mathrm{s}}(1,23)=2.60\right.$, $\left.M S_{\mathrm{e}}=25.90 ; F_{\mathrm{i}}(1,27)=2.08, M S_{\mathrm{e}}=38.17\right]$.

When the regular and exception words were matched on all factors known to be relevant to finding a masked onset priming effect, the effect was found with regular words but not with exception words. This result replicates that reported by Forster and Davis (1991) and indicates that the absence of the masked onset priming effect for the exception word targets cannot be attributed to the low value of $N$ in their exception words. The result is easily explained by the dual-route account, but not by the speech-planning account.

We will postpone discussion of how the speech-planning account might be modified to explain this result until after Experiment 2. In Experiment 2, we provide another test of the dual-route interpretation using the conditional naming task.

\section{EXPERIMENT 2}

In Experiment 2, the regular and exception word targets used in Experiment 1 were mixed randomly with nonword foils, and the subjects were instructed to read aloud the item only if it was a word. Forster and Davis (1991) had earlier reported that the masked onset priming effect was eliminated in this task and explained this observation within the dual-route framework. Specifically, they argued that the instruction to respond only if the item was a word encouraged subjects to "turn off" the nonlexical route, which is unnecessary and may lead to erroneous responding to nonword foils. If this account is correct, the regularity effect should also be eliminated in this task. This is because if the nonlexical route is turned off, there is no source of conflict in pronunciation for the exception words, and, hence, there is no reason to expect the exception words to be responded to more slowly than the matched regular words.

\section{Method}

Subjects. An additional 24 subjects from the same pool as in Experiment 1 took part in Experiment 2.

Design. The design was identical to that of Experiment 1.

Materials. The critical stimulus materials were the same 28 regular and 28 exception words used in Experiment 1. In addition, 56 nonword targets were selected to be the foils for the conditional naming task. These were all monosyllabic and matched with the word targets on length and $N$. Each of the word and nonword targets was preceded by a prime word of the same length as the target, selected according to the same criteria as those described in Experiment 1.

Apparatus and Procedure. The apparatus and procedure were identical to those of Experiment 1, except that the subjects were told that they would be shown a random mix of words and nonwords and

Table 2

Mean Naming Latencies (Reaction Times, in Milliseconds) and Percent Errors in Experiments 1, 2, and 3

\begin{tabular}{|c|c|c|c|c|c|c|}
\hline \multirow[b]{3}{*}{ Prime Type } & \multicolumn{4}{|c|}{ Word Type } & & \\
\hline & \multicolumn{2}{|c|}{ Regular } & \multicolumn{2}{|c|}{ Exception } & \multicolumn{2}{|c|}{ Regularity Effect } \\
\hline & RT & $\% E$ & RT & $\% E$ & RT & $\% E$ \\
\hline \multicolumn{7}{|c|}{ Experiment 1 (Pure blocks) } \\
\hline Onset & 490 & 0.6 & 565 & 3.0 & 75 & 3.1 \\
\hline Control & 504 & 1.5 & 569 & 5.3 & 65 & 3.8 \\
\hline Onset effect & 14 & 0.9 & 4 & 2.3 & & \\
\hline \multicolumn{7}{|c|}{ Experiment 2 (Conditional naming) } \\
\hline Onset & 741 & 4.7 & 774 & 8.6 & 33 & 3.9 \\
\hline Control & 751 & 5.7 & 774 & 8.3 & 23 & 2.6 \\
\hline Onset effect & 10 & 1.0 & 0 & -0.3 & & \\
\hline \multicolumn{7}{|c|}{ Experiment 3 (Mixed block) } \\
\hline Onset & 523 & 1.8 & 559 & 12.8 & 36 & 11.0 \\
\hline Control & 533 & 0.9 & 559 & 12.2 & 26 & 11.3 \\
\hline Onset effect & 10 & -0.9 & 0 & -0.6 & & \\
\hline
\end{tabular}


were instructed to read the item aloud as soon as possible only if it was a word.

\section{Results and Discussion}

The mean naming latency and percent error rates for the target words are shown in Table 2. The same planned contrasts as those in Experiment 1 were tested.

Naming latency. Averaged across prime type, the regularity effect was $28 \mathrm{msec}$ and was significant by subjects $\left[F_{\mathrm{s}}(1,23)=10.20, M S_{\mathrm{e}}=1,850.09\right]$, although it failed to reach significance by items $\left[F_{\mathrm{i}}(1,54)=1.97\right.$, $\left.M S_{\mathrm{e}}=13,304.66\right] \cdot{ }^{3}$ The $10-\mathrm{msec}$ masked onset priming effect for regular words was nonsignificant $\left[F_{\mathrm{s}}(1,23)<\right.$ $\left.1.0 ; F_{\mathrm{i}}(1,27)<1.0\right]$. The masked onset priming effect for exception words was also nonsignificant $\left[F_{\mathrm{s}}(1,23)<\right.$ $\left.1.0 ; F_{\mathrm{i}}(1,27)<1.0\right]$.

Error rate. Averaged across the prime type, the regularity effect was significant by subjects $\left[F_{\mathrm{s}}(1,23)=4.55\right.$, $\left.M S_{\mathrm{e}}=56.48\right]$, but nonsignificant by items $\left[F_{\mathrm{i}}(1,54)=\right.$ $\left.1.08, M S_{\mathrm{e}}=4.02\right]$. The masked onset priming effect for regular words was nonsignificant $\left[F_{\mathrm{s}}(1,23)<1.0\right.$; $\left.F_{\mathrm{i}}(1,27)<1.0\right]$, as was the effect for exception words $\left[F_{\mathrm{s}}(1,23)<1.0 ; F_{\mathrm{i}}(1,27)<1.0\right]$.

The results of Experiment 2 showed that in a conditional naming task, the masked onset priming effect for regular words observed in Experiment 1 was not reliable, replicating Forster and Davis's (1991) finding. However, the fact that the regularity effect was not eliminated raises problems for their dual-route interpretation, since it undermines the rationale for arguing that the nonlexical route was turned off in this task. How would the alternative, speech-planning account explain these findings?

\section{EXPERIMENT 3}

Although the regularity effect was not eliminated in Experiment 2, the size of this effect (averaged over prime types, $28 \mathrm{msec}$ ) was substantially smaller than that in Experiment $1(70 \mathrm{msec})$. One likely cause of this difference in the size of the regularity effect was the presentation of the regular and exception targets in separate blocks (Experiment 1) versus a mixed block (Experiment 2). A similar pattern of data was observed by Lupker, Brown, and Colombo (1997, Experiment 4): The size of their regularity effect was considerably larger when the regular and exception words were presented in separate blocks $(83 \mathrm{msec})$ than in the same mixed block $(31 \mathrm{msec})$. Lupker et al. noted that this reduction of effect size was found whenever fast items (e.g., high-frequency words, regular words) and slow items (e.g., low-frequency words, exception words) were mixed: Relative to pure blocks of fast items and slow items, fast items slowed down and slow items sped up when they were mixed. They proposed an interpretation of this finding couched in terms of a flexible time criterion. Specifically, individuals do not always initiate articulation as soon as an articulatory code is ready, but instead they adopt a flexible time criterion (deadline), such that the articulatory program for the stimulus might be allowed to develop beyond the point where the execution of the program could start, or its execution might be started when the program has not yet been fully developed. What determines the time criterion is the composition of items in a trial block: The idea is that in the pure blocks, the time criterion is set at a level that is appropriate for the type of stimulus in that block, whereas in mixed blocks, the time criterion must be set at an intermediate position.

One implication of this time criterion interpretation is that in a condition in which a smaller regularity effect is observed, the time criterion adopted for the regular words would have been slower than it could have been. The fact that the naming latency in the conditional naming task was substantially slower than that in Experiment 1 is also consistent with this possibility. It may be that this slower time criterion eliminated the masked onset priming effect, because the conflict resulting from a mismatch in onsets between the prime and target could be resolved during this delay in initiating articulation.

To test this possibility in Experiment 3, we used only the word stimuli, but unlike in Experiment 1, we presented them in the same block mixed randomly. From the time criterion perspective, it was expected that a slower time criterion would now be adopted for the fast (regular) words (and a faster time criterion for the slower exception words), resulting in a smaller regularity effect relative to that for the pure-block condition of Experiment 1. In addition, as in Experiment 2, we expected this slower time criterion to eliminate the masked onset priming effect for regular words.

\section{Method}

Subjects. An additional 24 subjects from the same population as in Experiment 1 participated for course credit.

Design. In Experiment 3, we used a standard naming task in which the regular and exception target words were mixed randomly, rather than being presented in separate blocks as in Experiment 1.

Materials. The stimulus materials were identical to those in Experiment 1.

Apparatus and Procedure. The apparatus, the instructions to the subjects, and the procedure were identical to those in Experiment 1 , except that the regular words and exception words were mixed randomly.

\section{Results and Discussion}

The mean latency and percent error rates are shown in Table 2.

Naming latency. Averaged across prime types, the regularity effect was $31 \mathrm{msec}$ and was significant $\left[F_{\mathrm{s}}(1,23)=\right.$ $\left.27.75, M S_{\mathrm{e}}=797.88 ; F_{\mathrm{i}}(1,54)=12.61, M S_{\mathrm{e}}=2,058.96\right]$. The 10-msec masked onset priming effect for regular words was nonsignificant $\left[F_{\mathrm{s}}(1,23)=3.47, M S_{\mathrm{e}}=360.09\right.$, $\left.p=.08 ; F_{\mathrm{i}}(1,27)=2.06, M S_{\mathrm{e}}=705.89\right]$. The masked onset priming effect for exception words was also nonsignificant $\left[F_{\mathrm{s}}(1,23)<1.0 ; F_{\mathrm{i}}(1,27)<1.0\right]$.

Error rate. The same planned contrasts as those for the naming latency data showed that, averaged across prime types, the regularity effect was significant $\left[F_{\mathrm{s}}(1,23)=\right.$ $\left.38.22, M S_{\mathrm{e}}=78.16 ; F_{\mathrm{i}}(1,54)=13.49, M S_{\mathrm{e}}=258.56\right]$. 
The masked onset priming effect for regular words was nonsignificant $\left[F_{\mathrm{s}}(1,23)<1.0 ; F_{\mathrm{i}}(1,27)<1.0\right]$, as was the effect for exception words $\left[F_{\mathrm{s}}(1,23)<1.0 ; F_{\mathrm{i}}(1,27)<1.0\right]$.

Combined analysis of Experiments 2 and 3. We combined the data from Experiments 2 and 3 and tested planned contrasts for the regularity effect, the masked onset priming effect for regular words, and whether each of these effects interacted with experiments. For latency, averaged across Experiments 2 and 3, the regularity effect was significant $\left[F_{\mathrm{s}}(1,46)=30.93, M S_{\mathrm{e}}=1,323.98 ; F_{\mathrm{i}}(1,54)=\right.$ $\left.5.09, M S_{\mathrm{e}}=10,241.54\right]$. It did not interact with experiments $\left[F_{\mathrm{s}}(1,46)<1.0 ; F_{\mathrm{i}}(1,54)<1.0\right]$. Averaged across Experiments 2 and 3, the masked onset priming effect for regular words was nonsignificant $\left[F_{\mathrm{s}}(1,46)=2.33, M S_{\mathrm{e}}=\right.$ $\left.1,107.63 ; F_{\mathrm{i}}(1,27)=1.94, M S_{\mathrm{e}}=2,036.92\right]$. This effect also showed no interaction with experiments $\left[F_{\mathrm{s}}(1,46)<\right.$ $\left.1.0 ; F_{\mathrm{i}}(1,27)<1.0\right]$. Finally, we tested whether the regularity effect was smaller in Experiments 2 and 3 combined than in Experiment 1. This interaction was significant $\left[F_{\mathrm{s}}(1,70)=18.06, M S_{\mathrm{e}}=1,464.88 ; F_{\mathrm{i}}(1,54)=13.98\right.$, $\left.M S_{\mathrm{e}}=792.88\right]$.

For error rate, averaged across Experiments 2 and 3, the regularity effect was significant $\left[F_{\mathrm{s}}(1,46)=37.11, M S_{\mathrm{e}}=\right.$ $\left.67.32 ; F_{\mathrm{i}}(1,54)=7.82, M S_{\mathrm{e}}=372.89\right]$. It interacted with experiments $\left[F_{\mathrm{s}}(1,46)=11.08, M S_{\mathrm{e}}=67.32 ; F_{\mathrm{i}}(1,54)=\right.$ $\left.5.28, M S_{\mathrm{e}}=164.87\right]$, indicating that the regularity effect was greater in Experiment 3 than in Experiment 2. Averaged across Experiments 2 and 3, the masked onset priming effect for regular words was nonsignificant $\left[F_{\mathrm{s}}(1,46)<\right.$ $\left.1.0 ; F_{\mathrm{i}}(1,27)<1.0\right]$. This effect also showed no interaction with experiments $\left[F_{\mathrm{s}}(1,46)<1.0 ; F_{\mathrm{i}}(1,27)<1.0\right]$. Finally, we tested whether the regularity effect was smaller in Experiments 2 and 3 combined than in Experiment 1. This interaction was significant by subjects $\left[F_{\mathrm{s}}(1,70)=4.36\right.$, $\left.M S_{\mathrm{e}}=61.55\right]$ but did not reach significance by items $\left[F_{\mathrm{i}}(1,54)=3.05, M S_{\mathrm{e}}=38.45, p=.09\right]$.

The analysis of Experiments 2 and 3 showed that the regularity effect was of comparable size in Experiments 2 and 3 and was smaller than in Experiment 1 . We take this as evidence that relative to the pure block condition in Experiment 1, a slower time criterion for regular words was adopted in Experiments 2 and 3 and that this slower time criterion was responsible for the absence of the masked onset priming effect for the regular words in these experiments.

Two points can be raised against this interpretation (we are grateful to Bob Lorch for these points). The first concerns the fact that although statistically it was nonsignificant, numerically the masked onset priming effect for the regular words in Experiments 2 and 3 was nonzero. Against this, we note that in a separate study that preceded the present study and used a different set of words, we replicated the pattern found here, in which the masked onset priming effect observed with regular words (when presented in a pure block) was eliminated both when they were mixed with the exception words and in a conditional naming task. In that study, one group of subjects $(n=24)$ performed both the mixed block naming task and the conditional naming task (with the assignment of items to the tasks counterbalanced between subjects), and another group of subjects $(n=24)$ performed the pure block naming task. In the analysis of regular words with at least three friends (the selection criterion used in the present study), the mean naming latencies for the onset-primed and control conditions were as follows: in the pure-block naming task, onset-primed, $517 \mathrm{msec}$, control, $541 \mathrm{msec}$; in the conditional naming task, onset-primed, $790 \mathrm{msec}$, control, $799 \mathrm{msec}$; in the mixed-block naming task, onset-primed, $566 \mathrm{msec}$, control, $559 \mathrm{msec}$. The masked onset priming effect of $24 \mathrm{msec}$ in the pure-block naming task was significant $\left[F_{\mathrm{i}}(1,35)=\right.$ $\left.6.43, M S_{\mathrm{e}}=1,577.93\right] .{ }^{4}$ The 9 -msec effect in the conditional naming task was nonsignificant $\left[F_{\mathrm{i}}(1,35)<1.0\right.$, $\left.M S_{\mathrm{e}}=6,616.56\right]$, as was the -7-msec effect in the mixedblock naming task $\left[F_{\mathrm{i}}(1,35)<1.0, M S_{\mathrm{e}}=1,609.5\right]$. Thus, the elimination of the masked onset priming effect for regular words as a function of task was a reliable phenomenon.

The second point that could be raised against the present delay-in-initiation-of-articulation interpretation is the fact that the naming latencies were much slower in Experiment 2 (conditional naming) than in Experiment 3 (mixedblock naming), yet the size of the masked onset priming effect was no smaller in Experiment 2. There are two comments to be made against this point. One is that statistically the masked onset priming effect did not differ from zero in either experiment. Second, this argument assumes that extra time (reflected in the longer response latency) might be used to develop the articulatory program further. To see that this is not necessarily the case, consider a hypothetical naming task in which a signal to respond is given either $2 \mathrm{sec}$ or $5 \mathrm{sec}$ after stimulus presentation. If the articulatory program can be developed fully within $2 \mathrm{sec}$, the extra $3 \mathrm{sec}$ available in the latter case are of no great benefit to the preparation of the articulatory program. Similarly, if the longer response latency to the regular words in Experiment 3 relative to those in Experiment 1 reflects a delay that is sufficient to resolve the conflict resulting from mismatching onsets between the prime and target, delaying the initiation of articulation any further is not expected to further reduce the size of the masked onset priming effect.

\section{GENERAL DISCUSSION}

To summarize the findings of the present study, a masked onset priming effect for regular words was found only when the regular words were presented in a pure block (Experiment 1); the effect was absent when a conditionalnaming task was used (Experiment 2) or when the regular and exception words were mixed randomly (Experiment 3 ). Exception words did not produce a reliable masked onset priming effect under any condition. The regularity effect was present in all three experiments, although it was larger in Experiment 1 than in either Experiment 2 or 3, which produced the same size effect. In this section, we argue that 
the dual-route interpretation has difficulty explaining all aspects of the data, but that they can be accommodated by an alternative account based on the notion that the masked onset priming effect has its origin in the planning of a speech response.

\section{The Masked Onset Priming \\ Effect With Regular Words}

The speech-planning account explains the masked onset priming effect as being due to a mismatch between the prime and target onsets, causing a conflict in the speech plans and argues that resolving this conflict costs time. This account explains the elimination of the masked onset priming effect for the regular words in Experiments 2 and 3 by assuming that when other factors (e.g., lexically contingent naming, the presence of slower items in the same block) produce a slower time criterion to be adopted for the initiation of articulation, the conflict resulting from a mismatch in onsets is resolved during the delay. The fact that the naming latencies to the regular words were slower in Experiments 2 and 3, along with the fact that the size of the regularity effect was smaller in these experiments than in Experiment 1, is taken as evidence that a slower time criterion for the regular words was adopted in the latter experiments.

In contrast, whereas the idea of time criterion itself is not incompatible with the dual-route account, there is no rationale within this account to explain the elimination of the masked onset priming effect when a slow time criterion was adopted. That is, because this account assumes that the masked onset priming effect arises during the computation of phonology, which takes place prior to the planning of speech output, it is unclear why delaying the initiation of articulation should have any impact on the effect.

\section{Absence of the Masked Onset Priming Effect with Exception Words}

In the present experiments, no masked onset priming effect was observed with exception words. Because these words were matched to the regular words on all factors known to modulate the size of the effect, we conclude that it is the exceptional spelling-to-sound correspondence that is responsible for the absence of masked onset priming effect.

Forster and Davis's (1991) own interpretation of the absence of masked onset priming effect for exception words was couched within a dual-route framework. Their argument is that the effect reflects the operation of the nonlexical route; hence, it would be absent when the pronunciation is "lexically controlled." Specifically, for exception words, "the nonlexical response must be inhibited before these words can be correctly pronounced" (p. 19). A problem with this account, however, is that it is incompatible with other aspects of the present datain particular, with the presence of a regularity effect in the conditional naming task. The presence of a regularity effect (comparable in size to that observed in a stan- dard mixed-block naming task) suggests that the nonlexical route was in operation, thus undermining the rationale for arguing that the generation of phonology is lexically controlled in this task.

We acknowledge that the absence of the masked onset priming effect for exception words is also difficult to accommodate within the speech-planning account as originally formulated. Specifically, if it is assumed that the conflict between the two phonologies (one generated by the lexical route, the other generated by the nonlexical route) generated for an exception word is resolved before the speech plan begins to be constructed, there is no reason why a masked onset priming effect would be absent for exception words. However, it may be that this assumption needs to be questioned. It is possible that the conflict observed between the two pronunciations of an exception word is not resolved at the level of abstract phonology, but during the segment-to-frame association process. We will defend this idea in the next section and, for now, point out simply that if the conflict in the two pronunciations generated for an exception word is resolved during speech planning, the conflict between the prime and target-onset phonemes might also be resolved during the period. 5

\section{The Locus of the Regularity Effect}

The regularity effect-that is, the cost in resolving the conflict between the two pronunciations generated for an exception word-is typically viewed as arising during the computation of phonology from orthography. What we are suggesting here, instead, is that its locus is farther downstream in the segment-to-frame association process; that is, the phonology generated by the nonlexical route and the one retrieved by the lexical route compete for a slot during the segment-to-frame association process.

M. Coltheart and Rastle (1994) had earlier argued against the late locus of the regularity effect on the grounds that "the effect of regularity of spelling-to-sound correspondence must be an effect on the time taken to compute a complete phonological representation, not the time taken to execute it serially after it has been fully computed" (p. 1208). Note, however, that their argument rests critically on the assumption that an articulatory response is executed immediately after a phonological representation has been computed. As mentioned in the introduction, speech production researchers (e.g., Levelt et al., 1999) have pointed out that further processing is necessary before an abstract phonological representation is realized as a speech response. Thus, the conflict between the two pronunciations generated for an exception word does not have to be resolved during the computation of phonology from orthography, but the resolution could occur in a later stage, prior to the initiation of articulation. Note also that the sequential nature of the regularity effect falls out naturally from the assumption that the regularity effect has a locus in a speech-planning process-specifically, during the segment-to-frame association process. Be- 
cause the segment-to-frame association process occurs left to right, and later segments cannot be prepared until the earlier segments are selected (Meyer, 1991), the cost of mismatching segments between the two pronunciations would be greater for earlier than for later positions.

The idea that the regularity effect has a late locus also has some empirical support. In a theoretical review of the role of phonology in reading, Frost (1998) cogently argued that the abstract phonology computed in silent reading tasks (such as semantic categorization and lexical decision tasks) need not be fully specified. From such a viewpoint, the regularity effect, which reflects fully specified phonology (to the level of speech output) is not necessarily expected in silent reading tasks. In line with this view, there is a growing body of evidence that the regularity effect is absent in silent reading tasks even when other phonological effects are found (cf. Berent, 1997; V. Coltheart, Patterson, \& Leahy, 1994). In contrast to these reports of the absence of the regularity effect in silent reading tasks, the effect has been reliably found in the naming (i.e., read aloud) task (e.g., Cortese, 1998; Seidenberg et al., 1984), consistent with the idea that the effect has its origin in speech planning.

In conclusion, we suggest that the two findings relating to the masked onset priming effect that have been interpreted within the dual-route framework-namely, the absence of the effect for exception words and the elimination of the effect for regular words in a conditional naming task-are both interpretable within the view that the effect has its origin in the segment-to-frame association process involved in the planning of speech output. In proposing this account, we noted the fact that none of the current computational models of reading aloud incorporates descriptions of how and when phonology is converted into a speech output. We look forward to future modeling endeavors that explicitly address this issue.

\section{REFERENCES}

Berent, I. (1997). Phonological priming in the lexical decision task: Regularity effects are not necessary evidence for assembly. Journal of Experimental Psychology: Human Perception \& Performance, 23 1727-1742.

Coltheart, M., Curtis, B., Atkins, P., \& Haller, M. (1993). Models of reading aloud: Dual-route and parallel-distributed processing approaches. Psychological Review, 100, 589-608.

Coltheart, M., \& Rastle, K. (1994). Serial processing in reading aloud: Evidence for dual-route models of reading. Journal of Experimental Psychology: Human Perception \& Performance, 20, 1197-1211.

Coltheart, M., Rastle, K., Perry, C., Langdon, R., \& Ziegler, J. (2001). DRC: A dual route cascaded model of visual word recognition and reading aloud. Psychological Review, 108, 204-256.

Coltheart, M., Woollams, A., Kinoshita, S., \& Perry, C. (1999). A position-sensitive Stroop effect: Further evidence for a left-to-right component in print-to-speech conversion. Psychonomic Bulletin \& Review, 6, 456-463.

Coltheart, V., Patterson, K., \& Leahy, J. (1994). When a ROWS is a ROSE: Phonological effects in written word comprehension. Quarterly Journal of Experimental Psychology, 47A, 917-955.

Cortese, M. J. (1998). Revisiting serial position effects in reading. Journal of Memory \& Language, 39, 652-665.

Cortese, M. J., \& Simpson, G. B. (2000). Regularity effects in word naming: What are they? Memory \& Cognition, 28, 1269-1276.
Forster, K. I., \& Davis, C. (1991). The density constraint on formpriming in the naming task: Interference effects from a masked prime. Journal of Memory \& Language, 30, 1-25.

Forster, K. I., \& Forster, J. C. (1990). DMASTR [on-line]. Available: http//www.u.arizona.edu/ kforster/dmastr/dmastr.htm

Frost, R. (1998). Toward a strong phonological theory of visual word recognition: True issues and false trails. Psychological Bulletin, 123, 71-99.

Hino, Y., \& LuPKeR, S. J. (2000). The effects of word frequency and spelling-to-sound regularity in naming with and without preceding lexical decision. Journal of Experimental Psychology: Human Perception \& Performance, 26, 166-183.

Kinoshita, S. (2000). The left-to-right nature of the masked onset priming effect in naming. Psychonomic Bulletin \& Review, 7, 133-141.

KINOSHITA, S. (2001). There goes the neighborhood: The role of neighborhood density in the masked onset priming effect. Manuscript submitted for publication.

KuČERA,H., \& Francis, W. N. (1967). Computationalanalysis of presentday American English. Providence, RI: Brown University Press.

Levelt, W. J. M., Roelofs, A., \& Meyer, A. S. (1999). A theory of lexical access in speech production. Behavioral \& Brain Sciences, 22, $1-38$.

Lupker, S. J., Brown, P., \& Colombo, L. (1997). Strategic control in a naming task: Changing routes or changing deadlines? Journal of Experimental Psychology: Learning, Memory, \& Cognition, 23, 570-590.

MEYER, A. (1991). The time course of phonological encoding in language production: Phonological encoding inside a syllable. Journal of Memory \& Language, 30, 69-89.

Plaut, D. C., McClelland, J. C., Seidenberg,M. S., \& Patterson, K. (1996). Understanding normal and impaired word reading: Computational principles in quasi-regular domains. Psychological Review, 103, 56-115.

Rastle, K., \& Coltheart, M. (1999). Serial and strategic effects in reading aloud. Journal of Experimental Psychology: Human Perception \& Performance, 25, 482-503.

Seidenberg, M. S., Waters, G. S., Barnes, M. A., \& Tanenhaus, M. K. (1984). When does irregular spelling or pronunciation influence word recognition? Journal of Verbal Learning \& Verbal Behavior, 23, 383404.

ZorZI, M. (2000). Serial processing in reading aloud: No challenge for parallel models. Journal of Experimental Psychology: Human Perception \& Performance, 26, 847-856.

Zorzi, M., Houghton, G., \& Butterworth, B. (1998). Two routes or one in reading aloud? A connectionist dual-route model. Journal of Experimental Psychology: Human Perception \& Performance, 24, $1131-1161$

\section{NOTES}

1. The issue of whether the masked onset priming effect reflects a benefit due to a match or a cost due to a mismatch of phonemes has yet to be established empirically. We note that this issue is immaterial to the two accounts of the effect we describe in this article.

2 . In the present article, we do not make a distinction between regularity and consistency, but conflate the two. Within the dual-route cascaded (DRC) model (M. Coltheart et al., 1993, 2001), regularity is a categorical variable defined on the basis of whether the pronunciation of the word matches that generated via the application of the graphemephoneme correspondence rules. Consistency, on the other hand, is a continuous variable, defined in terms of the ratio of frequency (either type or token) of friends (words that share the body that is pronounced the same way; e.g., mint, hint, and stint are friends) versus enemies (words containing the same body associated with a different pronunciation; e.g., pint and mint are enemies). Although regularity and consistency are separate dimensions, as pointed out by Cortese and Simpson (2000), they covary, so that many irregular words are also inconsistent. Hence, unless specifically controlled, irregular words will have more enemies and fewer friends than will regular words. It should also be noted that this definition of regularity is a feature of the DRC model, but is not an intrinsic feature of all dual-route frameworks (see M. Coltheart et al., 2001, p. 212). Thus, to allow comparison with other research that has investi- 
gated the regularity effect (and in particular, Forster \& Davis, 1991), we did not equate our regular and exception words on consistency.

3. However, this seems to be due to a few of the regular words being unfamiliar to the subjects. For example, the word HARK was considered by $38 \%$ of the subjects to be a nonword. When this word was excluded, the regularity effect was significant by items $\left[t_{\mathrm{i}}(53)=1.70, p=.048\right.$, one-tailed]. In this regard, it is relevant to note that the difference in the response latency for the regular words in the conditional naming task (mean $746 \mathrm{msec}$ ) versus the standard naming condition (Experiment 3, mean $528 \mathrm{msec}$ ) was $218 \mathrm{msec}$, which is substantially larger than the difference of $96 \mathrm{msec}$ observed in the equivalent conditions by Forster and Davis (1991, Experiment 1 vs. Experiment 6). Taken together with the fact that our word stimuli were low frequency (all less than 13 per million), this is consistent with the view that our subjects were unfamiliar with some of the words.

4. We report only the item analysis here because in the subjects analysis, the words used in the onset primed condition and the control condition were different words. Given that we restricted the analysis to a subset of words (words with at least three friends), they would not have been matched on various factors.

5. We should point out that Forster and Davis (1991) have hinted at a similar idea. In describing the absence of the masked onset priming effect for exception words, they noted that "the interfering effect of the masked prime is not detectable when there is a response conflict in- duced by the target itself" (p. 12). Although we agree with this description, we disagree with their interpretation that this response conflict is resolved by "inhibiting" the activity in the nonlexical naming system in order to output the correct response. Instead, our view is that any delay in initiating articulation permits the resolution of the conflict in speech planning due to a mismatch in onsets between the prime and target.

\section{APPENDIX \\ Critical Target Words}

\section{Regular}

wick, seam, pimp, hoop, wept, bust, wail, lard, doom, wipe, ditch, pact, coin, fetch, wade, sunk, peel, hark, wilt, bite, weed, lark, dock, wink, dense, bolt, toss, fuss

\section{Exception}

wand, soot, pint, hood, worm, bush, wasp, lure, deaf, wolf, dough, pour, comb, fuel, warn, sown, pear, hoof, warp, bowl, wool, lieu, dose, womb, debt, beau, tomb, feud

(Manuscript received October 23, 2000; revision accepted for publication October 17, 2001.) 